\title{
Food Safety on the Farm: Good Agricultural Practices and Good Handling Practices-Field Sanitation ${ }^{1}$
}

\author{
J. A. Lepper, J. De, C. R. Pabst, A. Sreedharan, R. M. Goodrich-Schneider, and K. R. Schneider²
}

As part of the Food Safety on the Farm series, a collection that reviews the generally recognized principles of GAPs as they relate to produce, primarily at the farm level and with particular focus on fresh Florida crops and practices, this publication focuses on GAPs relating specifically to field sanitation. The publications in this series can be found online at the EDIS website at http://edis.ifas.ufl.edu/ topic_series_food_safety_on_the_farm.

\section{Introduction}

The principles of Good Agricultural Practices (GAPs) were introduced by the US Food and Drug Administration (FDA) in the 1998 Guidance for Industry Guide to Minimize Microbial Food Safety Hazards for Fresh Fruits and Vegetables (FDA 1998). This guidance document for the fresh fruit and vegetable industry provided general guidelines for reducing the risk of contamination of fresh produce by microbial organisms. In response to this guidance, the United States Department of Agriculture (USDA) formally implemented the Good Agricultural Practices \& Good Handling Practices (GAPs and GHPs) audit verification program.

The USDA incorporated the Produce GAPs Harmonized Food Safety Standard into its GAP \& GHP audit program in 2011. The USDA further combined these two into a harmonized GAPs (H-GAPs) program in May 2018.
To make the oversight of food safety stronger and more efficient, the FDA and the USDA announced the alignment of the USDA H-GAP with the requirements of the FSMA's Produce Safety Rule (PSR) in June 2018. Since H-GAP is not equivalent to the Global Food Safety Initiative (GFSI) the USDA augmented the H-GAP audit to meet GFSI equivalence standards. The new USDA Harmonized GAP Plus+ audit is the only USDA GAP audit recognized as being GFSI technically equivalent. Regardless, all these programs adhere to the same basic principles of GAPs.

Under the new Food Safety Modernization Act (FSMA), GAPs are the foundation of the PSR. Up until the PSR, GAPs programs have been voluntary, imposed by the industry or buyers. Exceptions are the Florida Tomato Good Agricultural Practices (T-GAP) and Tomato Best Management Practices (T-BMP) regulations, which are state laws regulating the safe production of tomatoes. The current PSR mandates all non-exempt operations to follow the new FSMA federal guidelines (FDA 2018b), except for exempt commodities (as outlined in the regulation) and for those producers exporting to foreign countries. In those circumstances, voluntary GAPs programs may still be required by buyers or trade organizations.

The aim of both the mandatory PSR and the voluntary GAPs program is to reduce the foodborne illness burden

1. This document is FSHN10-12, one of a series of the Food Science and Human Nutrition Department, UF/IFAS Extension. Original publication date March 2012. Revised November 2017 and March 2019. Visit the EDIS website at https://edis.ifas.ufl.edu for the currently supported version of this publication.

2. J. A. Lepper, training specialist; J. De, postdoctoral research associate; C. R. Pabst, graduate student; A. Sreedharan, former postdoctoral research associate; R. M. Goodrich-Schneider, professor; and K. R. Schneider, professor; Food Science and Human Nutrition Department; UF/IFAS Extension, Gainesville, FL 32611.

The Institute of Food and Agricultural Sciences (IFAS) is an Equal Opportunity Institution authorized to provide research, educational information and other services

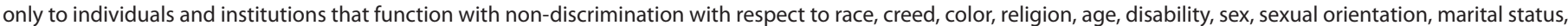

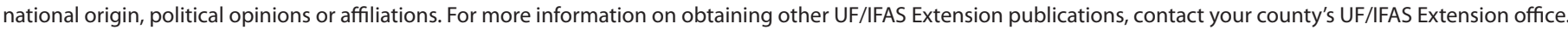
U.S. Department of Agriculture, UF/IFAS Extension Service, University of Florida, IFAS, Florida A \& M University Cooperative Extension Program, and Boards of County Commissioners Cooperating. Nick T. Place, dean for UF/IFAS Extension. 
associated with produce (FDA 2018a; FDA 2019). The FDA has compiled information from the Centers for Disease Control and Prevention (CDC) data regarding produce associated outbreaks that occurred between 1996 and 2010, where contamination was likely to have happened early in the production chain, during growing, harvesting, manufacturing, processing, packing, holding, or transportation (CDC 2018; FDA 2018a). An updated report from the CDC estimates that produce accounted for 51.6 percent $(21,280$ of 41,269) of all foodborne outbreaks in the United States from 1998 to 2016 (CDC 2018).

This fact sheet will focus on those activities and facilities that will be operational under GAPs as outlined in the Guide to Minimize Microbial Food Safety Hazards for Fresh Fruits and Vegetables (FDA 1998; FDA 2008). This fact sheet will specifically address those GAPs that pertain to sanitation in the field. How these practices relate to current regulatory requirements will also be summarized, demonstrating various ways for farmers to protect public health. Additional UF/IFAS Extension fact sheets in this series focus on other specific aspects of the GAPs program and how they relate to Florida crops and practices.

\section{Microbial Hazards}

Fresh produce can become contaminated with pathogenic microorganisms any time before, during, and after harvest. Sources of microbial hazards (pathogens) in the field can include soil, soil amendments (any input intentionally added to the soil), water, workers, and equipment. Improper management and cleaning of field equipment and unsanitary harvesting practices are examples of poor field sanitation that can increase the risk of contaminating fresh produce. It is important to note that poor management of human and other wastes in the field can significantly increase the risk of contaminating produce.

\section{Regulatory Background}

The enactment of the FSMA requires operations and facilities to comply with the specific regulations under which they are covered. However, certain businesses that fall short of meeting coverage criteria may have to comply with a different regulation. Thus, businesses may find it prudent to refer to other applicable regulations to guide the creation of a food safety plan.

Similar to the recommended GAPs derived from the Guide to Minimize Microbial Food Safety Hazards for Fresh Fruits and Vegetables, Title 21 of the Code of Federal Regulations (CFR), part 117, sections 20,37, and 40 delineate provisions for grounds of food plants, sanitation facilities and controls, and equipment and utensils, respectively (CFR 2016a; CFR 2016b; CFR 2016c; FDA 1998). These provisions may be relevant for operations that partially meet the farm definition (i.e., a farm mixed-type facility; FDA 2018c). They include requirements for proper maintenance and storage of equipment and pest control that can be applied towards controlling hazards in produce fields (CFR 2016a; CFR 2016b; CFR 2016c). Previously, these provisions were located in 21 CFR part 110 but have been reorganized into 21 CFR part 117 since the enactment of the FSMA. New considerations also include protection from allergen crosscontact, which may be a concern for a co-op packing tree nuts (e.g., coconuts, almonds, etc.) and/or peanuts along with other produce. Additionally, a farm mixed-type facility that creates a distinct raw agricultural commodity (RAC) processed beyond drying, dehydrating, packaging, and/ or labeling, such as dried, diced mangoes, would have to comply with these regulations unless that facility meets the specifications for an exemption or a qualified exemption. Conversely, if a farm or farm mixed-type facility dries or dehydrates a RAC to create a distinct commodity without further processing, such as dried, whole blueberries, that entity can meet the FSMA requirements for packing, packaging, and holding activities by either complying with the PSR found in 21 CFR part 112 or by complying with GMPs in subpart B of the Preventive Controls for Human Food (PCHF). Any activities of a farm mixed-type facility that fall within the farm definition are exempt from GMPs and may have to comply with the PSR.

Considering that the FSMA regulations are science-based and recommend minimum standards for safe food practices, growers must now be made aware of the new rules so they can comply with the more stringent regulations. State and local regulatory authorities can adopt mandatory and more specific regulations to improve food safety. Tomato operations in Florida must follow sanitary facility standards set out in the Tomato Good Agricultural Practices (TGAPs) during all steps of production (FDACS 2014). Land application of sewage biosolids is prohibited for Florida tomato growers due to T-GAPs restrictions, despite being allowed for use under the PSR if 40 CFR part 503 is met. These guidelines found in the Tomato Best Practices Manual have been made into rule (Chapter 5G-6) pursuant to Tomato Inspection Law Section 500.70 of the Florida Statutes, which took effect on July 1, 2008 (FAC 2007).

In response to and in recognition of growing food safety issues, the FSMA was passed by Congress and signed into law in January 2011 (FDA 2018b). The new law requires 
companies to implement a food safety program that significantly minimizes potential hazards and risks of foodborne illness. The PSR, one of the foundational rules of the FSMA, establishes standards to ensure safe growing, harvesting, packing, and holding of covered produce on farms. GAPs programs are currently intended as guidance, not as a regulation (except for round tomatoes grown in Florida), but are usually mandated or enforced by the buyers. Successful implementation of state-mandated regulations has set the precedent for the recent PSR covering commodities intended to be consumed raw or in their natural state. Currently, the PSR is required for all non-exempt operations that fall under the farm definition (FDA 2018c; FDA 2019). A flow chart with details on coverage and exemptions is available on the FDA website for operations to help determine compliance with the PSR (FDA 2015, FDA 2018d). In the PSR, subparts E (agricultural water) and F (biological soil amendments of animal origin and human waste) set requirements that aim to prevent pathogens introduced by the agricultural water (that may potentially contact the harvestable portion of produce or food-contact surfaces) and soil amendments during production (FDA 2019). Subpart I (domesticated and wild animals) of the PSR is directed at preventing biological hazards resulting from either domesticated or wild animals depositing excreta on covered produce. Whether covered or exempt, taking immediate steps to implement field sanitation GAPs will benefit a company's financial viability and overall produce safety. Moreover, even farms exempt from the PSR are subject to the provisions of the Food, Drug and Cosmetic Act (FD\&C Act) preventing adulterated food from entering commerce.

\section{Basic Principles for Microbial Food Safety}

Identifying basic principles of microbial food safety within the realm of growing, harvesting, packing, and transporting fresh produce will simplify GAP preparation by recognizing and addressing the principal elements known to give rise to microbial food safety concerns (FDA 2015; FDA 2019).

- Prevention of microbial contamination of fresh produce is favored over reliance on corrective actions once contamination has occurred.

- To minimize microbial food safety hazards in fresh produce, growers, packers, or shippers should use GAPs in areas over which they have control.

- Fresh produce can become microbiologically contaminated at any point along the farm-to-table food chain.
The major source of microbial contamination with fresh produce is associated with human or animal feces.

- Whenever water comes in contact with produce, its source and quality dictates the potential for contamination. Minimize the potential of microbial contamination from water used with fresh fruits and vegetables.

- Practices using animal manure or municipal biosolid wastes should be managed closely to minimize the potential for microbial contamination of fresh produce.

- Worker hygiene and sanitation practices during production, harvesting, sorting, packing, and transport play a critical role in minimizing the potential for microbial contamination of fresh produce.

- Follow all applicable local, state, and federal laws and regulations, or corresponding or similar laws, regulations, or standards for operators outside of the United States, for agricultural practices.

- Accountability at all levels of the agricultural environment (i.e., farm, packing facility, distribution center, and transport operation) is important to a successful food safety program. There must be qualified personnel and effective monitoring to ensure that all elements of the program function correctly and to help track produce back through the distribution channels to the producer.

\section{How to Control Potential Hazards}

For FSMA regulations such as the PSR to be successful, prerequisite programs such as GAPs are necessary to bolster such broad, scalable provisions. GAPs are critical in ensuring the safety and quality of fresh produce. The FDA identified the following GAPs that should be considered during harvesting and equipment maintenance to mitigate microbial risks in the field (FDA 1998).

\section{General Harvest Considerations}

- Clean and disinfect harvest containers prior to use.

- Inspect facilities for evidence of pests, such as rodents, birds, and insects.

- Clean and sanitize reusable containers before using them to transport fresh produce.

- Discard containers used for storing produce if they are damaged or cannot be thoroughly cleaned.

- Take care not to contaminate fresh produce that is washed, cooled, or packaged in the field. Contact with any source of pathogens (such as manure or biosolids, contaminated water, workers with poor hygiene, and unclean containers and boxes) can contaminate fresh 
produce in the washing, cooling, packaging, or storage process.

- Remove as much dirt and mud as practicable from the produce before it leaves the field. If removing mud in the field is not practical, it should be removed at the packing facility before sorting, grading, and packing.

\section{Equipment Maintenance}

Improperly managed field equipment, such as harvesting machinery, knives, containers, tables, baskets, packaging materials, brushes, buckets, etc., can be a source of contamination. Regularly cleaning and maintaining equipment can help prevent contamination of fresh produce. The following GAPs should be considered:

- Use harvesting and packing equipment appropriately and keep them clean. Equipment used for hauling garbage or manure should be cleaned and sanitized before coming in contact with or hauling fresh produce. Document the cleaning and sanitizing of equipment to help establish "clean breaks" between different lots of produce. If access to vehicle sanitation is limited, consider using dedicated vehicles to prevent cross contamination.

- Keep harvest containers clean to prevent cross-contamination of fresh produce. If containers are used repeatedly during a harvest, they should be cleaned after each load is delivered, prior to each reuse. Containers stored outside the physical operational plant should be inspected and/or cleaned before use.

- Assign responsibility for maintenance to the person in charge of managing equipment. The person in charge must know what and how equipment is being used, ensure equipment is functioning properly, and make sure equipment is cleaned and sanitized regularly.

\section{References}

Centers for Disease Control and Prevention (CDC). 2018.

National Outbreak Reporting System (NORS). https:// wwwn.cdc.gov/norsdashboard/

Code of Federal Regulations. 2016a. Current Good Manufacturing Practice, Hazard Analysis, and Risk-Based Preventive Controls for Human Food: Plant and Grounds. https://www.accessdata.fda.gov/scripts/cdrh/cfdocs/cfcfr/ CFRSearch.cfm?fr=117.20.

Code of Federal Regulations. 2016b. Current Good Manufacturing Practice, Hazard Analysis, and Risk-Based Preventive Controls for Human Food: Sanitary Facilities and Controls. https://www.accessdata.fda.gov/scripts/cdrh/ cfdocs/cfcfr/CFRSearch.cfm?fr=117.37.
Code of Federal Regulations. 2016c. Current Good Manufacturing Practice, Hazard Analysis, and Risk-Based Preventive Controls for Human Food: Equipment and Utensils. https://www.accessdata.fda.gov/scripts/cdrh/ cfdocs/cfcfr/CFRSearch.cfm?fr=117.40.

Florida Administrative Code. 2007. Rule 5G-6. Tomato inspection. https://www.flrules.org/gateway/ChapterHome. asp? Chapter $=5 \mathrm{G}-6$.

Florida Department of Agriculture and Consumer Services. 2014. Rule 5G-6. Tomato Best Practices Manual. https:// www.flrules.org/Gateway/reference.asp?No=Ref-05931.

Food and Drug Administration (FDA). 1998. Guide to Minimize Microbial Food Safety Hazards for Fresh Fruits and Vegetables. https://www.fda.gov/regulatory-information/ search-fda-guidance-documents/guidance-industry-guideminimize-microbial-food-safety-hazards-fresh-fruits-andvegetables

Food and Drug Administration (FDA). 2008. Guidance for Industry: Guide to Minimize Microbial Food Safety Hazards of Fresh-cut Fruits and Vegetables. https://www.fda.gov/ Food/GuidanceRegulation/GuidanceDocumentsRegulatoryInformation/ProducePlantProducts/ucm064458.htm.

Food and Drug Administration (FDA). 2015. Standards for Produce Safety Coverage and Exemptions/Exclusions for 21 Part 112. https://www.fda.gov/downloads/Food/ GuidanceRegulation/FSMA/UCM472499.pdf.

Food and Drug Administration (FDA). 2018a. Produce Safety Standards. https://www.fda.gov/food/guidanceregulation/fsma/ucm304045.htm

Food and Drug Administration (FDA). 2018b. Food Safety Modernization Act. http://www.fda.gov/Food/GuidanceRegulation/FSMA/default.htm.

Food and Drug Administration (FDA). 2018c. FSMA Final Rule for Preventive Controls for Human Food. https://www. fda.gov/food/guidanceregulation/fsma/ucm334115.htm.

Food and Drug Administration (FDA). 2018d. Compliance Dates. https://www.fda.gov/Food/GuidanceRegulation/ FSMA/ucm540944.htm.

Food and Drug Administration (FDA). 2019. FSMA Final Rule on Produce Safety. http://www.fda.gov/Food/GuidanceRegulation/FSMA/ucm334114.htm. 


\section{Resources}

Chapman, B., \& Danyluk, M. 2013. Establishing Lot Size

through Sanitation Clean Breaks in Produce Packing Facili-

ties. FSHN13-10. UF/IFAS Extension, Gainesville, FL

32611. http://edis.ifas.ufl.edu/fs234

Schmidt, R. 2009. Basic Elements of Equipment Cleaning and Sanitizing in Food Processing and Handling Operations.

FS14. UF/IFAS Extension, Gainesville, FL 32611. http://

edis.ifas.ufl.edu/fs077 